\title{
AS QUESTÕES ETNICO-RACIAIS EM ESCOLAS ESTADUAIS NA REGIÃO DO BREJO PARAIBANO
}

\author{
DE LAS CUESTIONES ETNICO-RACIALES EN ESCUELAS ESTADALES EN LA \\ REGIÓN DEL BREED PARAIBANO
}

\author{
THE ETHNIC-RACIAL ISSUES IN STATE SCHOOLS IN THE BRAZILIAN \\ PARAIBANO REGION
}

Ana Cristina Silva DAXENBERGER ${ }^{1}$

\begin{abstract}
RESUMO : Educar para as relações étnico-raciais é romper com o posicionamento tácito da escola sobre as questões de discriminação racial e valorização da diversidade presente no Brasil. Sendo assim, nossa pequisa objetivou avaliar como está se constituindo a educação para as relações étnico-raciais em escolas estaduais do ensino médio, em três munícipios: Areia, Alagoa Grande e Remígio/PB. Utilizamos um questionário semi-estruturado, respondido por 622 estudantes; 4 gestores e 12 professores. Podemos afirmar que ainda precisa de debates sobre as questões étnicoraciais dentro da escola, sobretudo, para a superação da discriminação e o preconceito racial; oferecer fomação docente e melhorar a qualificação os materiais a serem utilizados.
\end{abstract}

PALAVRA-CHAVE: Etnicidade. Lei 10.639/03. Currículo escolar.

RESUMEM: Educar para las relaciones étnico-raciales y romper con el posicionamiento tácito de la escuela sobre cuestiones de discriminación racial y valorización de la diversidad presente no Brasil. Siendo así, nuestra pequeña objetivó evaluar cómo se está constituyendo una educación para las relaciones étnicas-raciales en escuelas estatales de la enseñanza media, en tres municipios: Areia, Alagoa Grande y Remigio / PB. Utilizamos un cuestionario semiestructurado, respondido por 622 alumnos; 4 gestores y 12 profesores. Podemos afirmar que todavía necesita debates sobre las cuestiones étnicas-raciales dentro de la escuela, sobre todo, para una superación de la discriminación y el prejuicio racial; Ofrecer apoyo docente y mejorar la calificación de materiales a ser utilizados.

PALABRAS CLAVE: Étnico. Ley 10.639/03. Currículo escolar.

ABSTRACT: To educate for ethnic-racial relations is to break with the tacit positioning of the school about the racial discrimination and appreciation and recognize the diversity present in Brazil. Our research aimed to evaluate how education for ethnic-racial relations is being constituted in high schools in three cities: Areia,

${ }^{1}$ Universidade Federal da Paraíba (UFPB), Professora do Departamento de Ciências Fundamentais e Sociais. Doutora, em Educação Escolar. Líder do grupo de Pesquisa Educação, Desenvolvimento Sustentável e Inclusão Social/CNPq. Assessora do Comitê de Inclusão e Acessibilidade da UFPB; Membro do NEABI/UFPB. Extensionista na área de inclusão escolar e social. E-mail: ana.daxenberger@gmail.com 
Alagoa Grande and Remígio / PB. We used a semi-structured questionnaire, answered by 622 students; 4 managers and 12 teachers. We can say that we still need debates on ethnic-racial issues within the school, above all, to overcome discrimination and racial prejudice; offer teacher training and improve the qualification materials to be used in the school.

KEYWORDS: Ethnicity. Law 10.639/03. School Curriculum.

\section{Introdução}

Desde que a Lei 10.639/2003, que propõe a alteração da LDB 9.3.94/06, no tocante à inclusão do ensino da história da África e suas contribuições à cultura brasileira, tivemos várias pesquisas que retratam a aplicabilidade da lei no âmbito escolar. Na maioria delas, os pesquisadores identificam que há mais de uma década pouco tem se ampliado no fortalecimento de uma educação para as relações étnicoraciais que incentive a valorização e o reconhecimento da população negra e seus descendentes, oriunda da diáspora africana imposta pelos portugueses durante o período de colonização e exploração no Brasil (CAVALLEIRO, 2003, DAXENBERGER, 2016; SILVA, 2012; GUEDES et al.2013).

Pensar em uma educação para as relações étnico-raciais é romper com o posicionamento tácito da escola sobre as questões de discriminação racial, desigualdade social e valorização das diferentes culturas que compõe o Brasil. A pluridade cultural, étnica, racial, religiosa e os mais diversos aspectos identitários estão presentes no cotidiano escolar e devem ser temática de discussão e estudos no currículo escolar para que a escola possa formar um educando crítico e reconhecedor da diversidade que compõe a essencia humana. Segundo Morin (2001), o ser humano é um ser complexus que se constitui durante as relações sociais e que compreende o mundo em que está inserido por meio da educação que a sociedade lhe oferece, durante as diferentes relações sociais. E por muitas vezes estas relações estão carregadas de ideologia que prima pela manutenção do status quo de uma sociedade branqueadora e de poder superior. Sendo assim, a escola como uma das principais instituições de formação humana na sociedade, deve primar para garantir que os seus membros (profissionais da educação, estudantes e comunidade) tenham acesso ao conhecimento crítico sobre a história de seu próprio povo e suas culturas; com a construção de novas práticas 
educativas em que valorize a diversidade e crie ações propositivas de inclusão escolar e social, sobretudo, que fortaleça a identidade negra.

Santos e Prado (2014, p. 120) afirma que são "múltiplas as origens da omissão com relação à pluralidade cultural, quando algumas vezes a escola subordina uma cultura a outra ou divulga uma concepção de cultura uniforme e padronizada, não reconhecendo o grande mosaico linguístico e cultural brasileiro". O que em nosso entendimento, acaba por muitas vezes, a escola assumindo um papel de reprodutora dos compormentos discriminatórios e fortalecedora da manutenção de uma sociedade que não reconhece todos como sujeitos de direitos e capazes de exercer sua cidadania.

É mister materializar as Leis $10.639 / 03$ e a 11.645/2008 que tratam do ensino da história da África e suas contribuições à cultura brasileira. Isto já está previsto em outros documentos oficiais que foram publicados pelo Mec ou pelo Conselho Nacional de Educação (Diretrizes Curriculares Nacionais para a Educaçãodas Relações Étnicoraciais e para o Ensino de História e Cultura afro-brasileira, 2004; Parecer 3 do Conselho Nacional de Educação, 2004; Resolução 4 do Conselho Nacional de Educação, 2010). Mesmo com as últimas alterações da LDB 9.394/96, trazidas pela reforma do ensino em 2017, Lei 13415/2017; o conteúdo relacionado às respectivas legislações, decretos e normativas que tratam sobre o ensino da história da África e suas contribuições se mantém como exigência no currículo escolar, por meio do art. 26 e 26 A, art. 79 e 79 A.

Diante do exposto, apresentamos neste estudo, os resultados e conclusões de nossa pesquisa que teve com o objetivo avaliar como está se constituindo a educação para as relações étnico-raciais de acordo com as Leis Federais de $n^{0}$ 10.639/03 e 11.645/08, em escolas estaduais do ensino médio, no entorno do campus II, Universidade Federal da Paraíba (UFPB), especificamente em três munícipios: Areia, Alagoa Grande e Remígio.

\section{A educação para as relações etnico-raciais: uma possibilidade de superação da desigualdade social}

O estudo da história sobre a população afro-descendente, no Brasil, não é muito explorada, o que deixa a desejar, em uma sociedade que embora tenha mais de cem anos de República Federativa, ela, ainda, é preconceituosa, discriminatória, individualista e com grande desigualdade social. 
O incentivo ao ensino e aprendizagem dos aspectos relacionados à educação para as relações etnico-raciais pressupõe que a escola reconheça a diversidade humana como condição sine qua non para a elaboração de suas práticas; reforme o currículo escolar; fortaleça as práticas de aceitação da diferença; fortaleça a identidade dos sujeitos envolvidos durante o processo educativo; e mais, do que tudo, tenha um olhar crítico sobre como foi construído as relações sociais, no Brasil, e ofereça um processo de reflexão sobre a contemporaneidade, para que os sujeitos possam desenvolver sua cidadania e construir sua própria história como descendentes afro-brasileiro ou não dignos de melhoria de condições de vida. Vale ainda ressaltar que a formação docente torna-se um dever do Estado, pois muitos dos professores que estão lecionando nas escolas públicas e/ou privadas, não tiveram em sua formação inicial, um estudos crítico e aprofundado sobre os conteúdos exigidos pelas Leis 10.639/03 e 11.645/08. Isto muitas vezes pode dificultar na construção de práticas coesas com os princípios da eduação para as relações eticno-raciais, pois como Freire (1997) diz ninguém ensina aquilo que não domina.

O estudo dos conteúdos sobre a história da África e suas contribuições e sobre os aspectos vinculados à educação para as relações étnico-raciais são fundamentais também para construir uma educação antirracista e superaçãodo mito da democracia racial que é presente no Brasil. Fernandes (2005) retrata que apesar da predominância marcante da cultura de matriz européia por força da colonização ibérica no nosso país, a cultura tida como dominante não conseguiu, apagar da história as culturas indígenas e as africanas. O que ocorreu foi que o colonizador europeu deixou-se influenciar pela riqueza diversificada dos índios e negros. Portanto, o modelo organizacional implantado pelos "brancos" se fez presente no campo educacional e cultural, por este motivo a diversidade está nos corredores da escola, nas relações sociais, mas nem sempre é reconhecida nas práticas educativas e/ou presente nos livros didáticos.

Para o Fernandes (2005) apesar do fato inquestionável de quem somos, em virtude da nossa formação histórica e social, com uma multiplicidade racial e étnica; a escola brasileira não aprendeu a conviver com essa realidade, e que por consequência não consegue fortalecer a identidade das crianças e jovens descendentes afro-brasileiros que muitas vezes acabam alimentando os índices da população com menor nível de escolarização, fraco poder econômico e na camada social em que encontramos a maior desigualdade social. 
De acordo com os dados do IPEA (2014), a população brasileira é 203.190.039 habitantes. Divididos por regiões da seguinte forma: Região Norte com 17.284.768 habitantes, Região Nordeste com 56.269.744, Região Sudeste possui 56.269.744, Região Sudeste 85.290.488 habitantes, Região Sul 29.077.184 e Região Sudeste com 15.267.855 habitantes. A população que se declara preta, até o ano de 2014, era de 17.430.338 habitantes distribuídos nas cinco regiões brasileiras. A população branca chegava ao número de 92.405.543, no ano de 2014. Segundo esses números observamos que a população branca tem mais indivíduos do que a população preta. Não obstante, se somarmos a população preta e parda (as quais consideramos como população negra, assim como o Movimento Negro Brasileiro considera), estas superam a população branca. Somando a população parda $45,0 \%$ com a população preta $8,6 \%$, temos o total de 53,8\% contra 45,5\% da população branca, até o ano de 2014.

Estes dados estatíticos fortalecem a ideia que o Brasil foi e continua sendo um país miscigenado, com a inter/multiculturalidade presente na sociedade. Mesmo com a ampliação da autodeclaração da população negra, ainda há muito que se fazer quanto às desigualdades sociais. E estas estão presentes em todos os segmentos da nossa sociedade. As pessoas de perfil étnico-racial negro apresentam os menores níveis de escolarização e muitas são discriminadas sociais devido a baixa escolarização, entre elas a desigualdade trabalhista (IPEA, 2014).

Com relação aos níveis de escolaridade, segundo o $\operatorname{IPEA}(2014, \mathrm{~s} / \mathrm{p})$ no diz o seguinte:

[...] Na população branca, o percentual de pessoas com nove anos ou mais de estudo era de $39,8 \%$, em 2001, e subiu para 55,5\% em 2012; na população negra, o percentual de pessoas com igual escolaridade passou de $22,5 \%$, em 2001, para 41,2\%, em 2012. [...] no que se refere à escolarização, as desigualdades entre brancos e negros estão relacionadas a múltiplos fatores, tais como renda familiar e acesso a bens públicos. As consequências de maior envergadura para a população negra se traduzem, entre outros fatores, em menor frequência escolar.

As pesquisas do IPEA (2014) mostram que os níveis de educação da população negra continuam inferiores aos níveis de educação da população branca. As diferenças ocorrem em todos os níveis educacionais, sendo que o ensino superior possui maior taxa de desigualdade. No período de avaliação, do ano de 2012, as taxas de negros e brancos foram quase igualadas, o que em nosso entendimento, as políticas de acesso ao ensino 
superior trazidas pelo Governo Lula tem contribuído significativamente na mudança deste quadro social.

Os dados revelam que as taxas de escolarização líquida de negros são significativamente inferiores às de brancos nos ensinos médio e superior. $\mathrm{O}$ mesmo acontece para cobertura escolar na faixa de até cinco anos de idade. Cabe destacar, no entanto, que nos ensinos médio e superior a desigualdade entre brancos e negros sofreu relevante redução no período analisado. No ensino médio, a frequência líquida dos jovens negros era metade daquela apresentada pelos brancos; em 2012, a diferença passou a ser de três quartos. Por sua vez, ainda que o ensino superior seja o nível com maior desigualdade entre as taxas de negros e brancos (a taxa dos negros foi inferior à metade da taxa dos jovens brancos em 2012), trata-se da etapa em que se verificou maior evolução da taxa da população negra (cerca de 200\%). Para o ensino fundamental, as taxas de escolarização líquida praticamente se igualaram em 2012. (IPEA, 2014).

Considerando que a educação é essencial para a inserção no mundo do trabalho e na qualidade de vida das pessoas, identificamos por meios destes dados estatísticos que a população negra brasileira tem permanecido à margem das melhores condições de trabalho por consequência da falta de boa qualidade de ensino e, pelo não fortalecimento de sua própria identidade como sujeito de direito. Como mostra Abramo (2006), as melhores condições de trabalho com maiores salários são preenchidos em maior número por pessoas brancas. Como nos mostra ABRAMO (2006), o mercado de trabalho brasileiro está marcado por significativas e persistentes desigualdades de gênero e raça e esse é um aspecto que deve ser levado em conta nos processos de formulação, implementação e avaliação das políticas públicas em geral, e, em particular, das políticas de emprego, inclusão social e redução da pobreza ABRAMO (2006).

\section{Procedimentos metodológicos}

Esta pesquisa tem a abordagem quanti-qualitativa que apresenta dados numéricos sobre o objeto de pesquisa e traz uma análise crítica sobre os dados qualitativamente, de maneira que possamos compreender como está a implantação dos aspectos exigidos pelas Leis 10.639/03 e 11.645/08, no contexto histórico da educação brasileira. Como instrumento de pesquisa, optamos por utilizar o questionário semi- 
estruturado, aplicado com 622 educandos, 4 diretores e 12 professores, das áreas de História, Filosofia, Artes, Matemática, Português e Geografia, das Escolas Estaduais de Ensino Médio da Região do Brejo Paraibano (duas escolas no Município de Areia, uma em Alagoa Grande e uma em Remígio). Todos municípios são circunvizinhos ao campus II, da UFPB. Como critério de escolha das escolas, utilizamos o maior número de alunos matriculados e ter ensino médio.

Os dados foram analisados por temáticas de estudo e estão assim organizados: a Concepção dos educandos sobre o ensino da história da África e cultura afro-brasileira; e, posteriormente, a visão dos gestores e professores sobre a temática em estudos.

\section{A concepção dos alunos sobre o ensino da história da África e cultura afro- brasileira}

Antes de apresentarmos os dados específicos sobre o objeto de pesquisa, é importante caracterizarmos o perfil dos educandos que participaram da pesquisa, uma vez que os dados de identificação etnico-racial e religiosa definem quem são os sujeitos e este aspecto é importantíssimo ao se discutir as questões etnico-raciais dentro do ambiente escolar.

Participaram da pesquisa 261 discentes do sexo masculino, 2 não se identificaram e 359 do sexo feminino, como tem no IBGE (Instituto Brasileiro de Geografia e Estatística) a população feminina no Brasil é a maior que a masculina, essa diferença subiu em quase 600 mil pessoas e agora o País tem 6,353 milhões de mulheres a mais do que homens, segundo a PNAD (Pesquisa Nacional por Amostra de Domicílios) 2014, divulgada pelo IBGE (Instituto Brasileiro de Geografia e Estatística). Os discentes possuem idades entre 15 a 28 anos, sendo 53\% residentes da zona rural, $43 \%$ da zona rural e $4 \%$ não responderam.

Os educandos possuem renda familiar de um salário mínimo cerca de 74\%, 16\% ganham de dois a três salários mínimos, $2 \%$ recebem acima de três salários mínimos e $8 \%$ não declararam sua renda. Assim analisamos que a maioria dos alunos possue uma vida simples da zona rural sendo beneficiários de programas sociais, como bolsa família fornecida pelo Governo (66\%); 30\% não recebe qualquer auxílio e $4 \%$ não assinalaram a questão.

Ao perguntarmos qual é a religião dos educandos, notamos que a religião Católica (65\%) ainda é a religião mais procurada pelos fiéis e o "Brasil ainda é a maior 
nação católica do mundo[...]”2; 27\% dos educandos são evangélicos; $5 \%$ não responderam; $2 \%$ são praticantes de umbanda e/ou candomblé; 3\% nenhuma religião. Para Gualberto (2011, p. 12) os praticantes de religiões de matriz africana, como Candomblé e Umbanda são as principais vítimas de intolerância religiosa no Brasil, caracterizando os casos mais frequentes e graves de fanatismo religioso. No entanto, o Brasil, tem leis específicas que tratam sobre o direito de liberdade religiosa do indivíduo e consideram crime a prática de discriminação ou preconceito contra religiões (Constituição Federal, 1988, art. 5², inciso VI; Leis contra Intolerância Religiosa, 7.716/89, Lei no 9.459/97, e a 11.635/2007. É inviolável a liberdade de consciência e de crença, sendo assegurado o livre exercício dos cultos religiosos e garantida, na forma da lei, a proteção aos locais de culto e as suas liturgias.

Outro levantamento presente na pesquisa foi como se definem os alunos no ponto de vista racial, $33 \%$ pardos, $32 \%$ moreno, $16 \%$ brancos, $13 \%$ negros, $4 \%$ amarelo, $1 \%$ preto, $1 \%$ indígena. No entanto, ao discutirmos sobre os aspectos etnicoraciais, não podemos simplesmente tratar de questões hereditárias, descontextualizadas das questões sociais e culturais. O ser humano é constítuido ao saber das relações, sendo essencialmente um ser complexus (MORIN, 2001), ou seja, o ser humano não pode ser considerado somente nos aspectos biológicos, pois somos o que somos pela formação cultura e social que adquirimos por meio da educação, a qual muitas vezes sofre influência ideológica de valores impregnados pela política sócio-econômico das Nações em que o ser está inserido.

Isto é perceptível ao refletirmos sobre os dados de identificação etnico-racial, pois $32 \%$ se consideram morenos, o que ao longo da história brasileira, era um termo considerado para branquear a população negra brasileira e assim ser mais reconhecido socialmente. Entre os educandos participantes, temos $79 \%$ de negros, para $16 \%$ de brancos, $4 \%$ amarelos e $1 \%$ indígena. Vale explicitar que utilizamos o termo moreno por ser muito utilizado entre os participantes; todavia, entendemos que tanto a população parda, negra, preta ou morena compõe a população negra, assim como o Movimento Negro brasileiro considera as categorias de autoidentificação. As demais categorias são as mesmas usadas pelo IBGE para o censo demográfico.

Não podemos deixar de informar que as cidades de Areia, Remígio e Alagoa Grande, onde a pesquisa foi desenvolvida, tem relações diretas com a colonização

2 Pesquisa disponível em: <http://g1.globo.com/jornal-nacional/noticia/2013/07/brasil-ainda-e-o-maiorpais-catolico-do-mundo-mesmo-com-reducao-de-fieis.html>. Acesso em: 28 jul. 2017. 
portuguesa e a exploração da mão de obra do negro, nas lavouras de cana de açúcar, durante o século XIX. Estas cidades tinham como principal atividade econômica a plantação de cana-de-açúcar, a produção de rapadura e cachaça; motivo este que grande parte da população das escolas públicas tem relações diretas com a descendência africana. O que em nosso entendimento, ratifica ainda mais a importância das escolas e educadores desenvolveram um trabalho educativo para as relações etnico-raciais, de maneira a contribuir na valorização do próprio público atendido por ela e a superação da discriminação racial.

A Lei 10.639, aprovou uma reivindicação histórica do Movimento Negro Brasileiro ao "instituir obrigatoriedade do ensino da História da África e da Cultura Afro-Brasileira no currículo oficial da rede de ensino" (BRASIL). Porém muitos professores não têm domínio de trabalhar em sala conteúdos sobre a temática de forma a garantir a superação da desigualdade social e a diminuição da discrimincação racial. Questionamos aos educandos se os professores das escolas desenvolvem atividades sobre a África: $51 \%$ responderam que sim, $48 \%$ que não e $1 \%$ não responderam. Um pouco mais da metade desenvolve atividades, porém é alarmante o percentual dos que não amplia o conhecimento de seus alunos sobre as questões afrodescendentes. Para Oliva (2003); Gonçaçves (2106 e Santos e Prado (2014) esta problemática se dá pela falta de formação docente, a qual muito professores não tiveram estes conteúdos durante sua formação inicial e porque a grande maioria dos livros didáticos não tratam adequadamente sobre a África e suas contribuições à cultura brasileira, de maneira critica.

Outro ponto levantado foi se a escola já desenvolveu alguma atividade sobre racismo e /ou preconceito racial: $69 \%$ declararam que sim, $28 \%$ responderam que não e $3 \%$ não responderam. Muitas vezes as situações de racismo e /ou preconceito ocorrem no ambiente escolar mais precisamente dentro das salas de aula. Com isso seria importante que o educador estivesse atento a qualquer forma de tratamento discriminatório, como gestos, tom de voz e outras atitudes que possam degradar a pessoa do educando. Porque em qualquer tipo de discriminação, seja qual for o formato do preconceito racial, o estudante que sofre esse abuso pode chegar até à "reprovação, dependendo do dano psicológico e emocional causado à criança” (CAVALLEIRO, 2003, p. 81-89).

Ao perguntar sobre as formas de atividades realizadas para a superação da discriminação, constatamos que a palestra (57\%) e atividades em sala de aula (17\%). 
Estes dados nos possibilita afirmar que há necessidade dos educadores assumirem a responsabilidade social, ampliando o debate e efetivar ações para a superação da discriminação. Ainda responderam (17\%) que os professores não realizam nenhuma atividade; somente $2 \%$ realizam projetos didáticos; $1 \%$ mini-curso; $1 \%$ oficinas; e $5 \%$ não responderam a questão.

De acordo com Galhardo (2004 apud SOUZA, FERRAS E CHAVES, 2007, p.437) [...] a escola possui a responsabilidade de transmitir a memória cultural e os valores produzidos historicamente pelo ser humano no contato com a natureza e nas relações sociais. Por este motivo, poderia dinamizar as práticas educativas e suscitar discussões sobre as práticas de inclusão sobre o aspecto etnico-racial.

Outra questão levantada foi se os educando acham importante os professores e a escola trabalharem os temas racismo e preconceito: $3 \%$ não consideram; $2 \%$ não respondeu a questão e $95 \%$ responderam que sim. Destacamos as falas abaixo por considerarmos significativas: "Pois ainda existem pessoas preconceituosas" (A6); " Para que todos saibam que somos todos iguais" (A7); "Para que as pessoas entendam que não devemos julgar ninguém pela sua cor ou raça" (A8); "Porque é bom conscientizar as pessoas sobre tal tema" (A9); "Para as pessoas entenderem que todo mundo é igual independente de qualquer coisa" (A10); "Porque devemos lembrar que negro também é gente" (A11).

O que constatmos é que a maioria dos alunos já tem uma sensibilidade para a causa em estudo (superação da discriminação e preconceito), expressando a importância que o tema tem para cada um e para a sociedade como um todo. Cavalleiro (2003, p. 34) afirma que, [...] "o racismo é um problema que está presente no cotidiano escolar, que fere e marca, profundamente, crianças e adolescentes negros. Mas, para percebê-lo, há a necessidade de um olhar crítico do próprio aluno".

"Racismo é uma ideologia entre os grupos humanos" (Programa Nacional de Direitos Humanos, 1998, p. 12). Assim ao questionar aos alunos se eles já sofreram algum tipo de preconceito ou racismo: $41 \%$ dos alunos não possuem relatos de nenhum tipo de discriminação e/ ou preconceito; enquanto que $59 \%$ já sofreram algum tipo de racismo ou preconceito, sendo: $30 \%$ de corpo, $28 \%$ não tem experiência, $2 \%$ de Gênero, $14 \%$ de lugar, $4 \%$ não responderam, $2 \%$ condição financeira, $6 \%$ de religião e $14 \%$ de racismo. Como indica no gráfico 2:

Para Moura (1994, p. 160): 
O racismo brasileiro [...] na sua estratégia e nas suas táticas agem sem demonstrar a sua rigidez, não aparece à luz, ambíguo, meloso, pegajoso, mas altamente eficiente nos seus objetivos. [...] não podemos ter democracia racial em um país onde não se tem plena e completa democracia social, política, econômica, social e cultural.

De fato, como afirma o autor essas abordagens que indicam a diminuição de expressões racista são algo muito superficial, pois muitas pessoas ainda hoje, em pleno século XXI, ainda vivem oprimidas e sendo desrespeitadas devido à discriminação e ao racismo. Não obstante que a grande parcela da população pesquisa ser de origem negra, não foi raro encontrarmos dados que esta população vem sendo vitimizadas dentro do espaço escolar, entre os seus pares. Somando os índices de racismo, condição financeira e lugar onde mora (são aspectos relacionados à população negra participante da pesquisa), identificamos $24 \%$ dos participantes que já sofreram discriminação, sendo somente superado pelo aspecto corpo.

Estes dados nos remetem à reflexão sobre a importância do agir educativo do professor, quanto a estes aspectos, estando atento a qualquer forma ou ato de discriminação existente dentro ou fora da sala de aula. Tais como gestos, tom de voz e outras atitudes que possam expor o educando às situações de bullying ou discriminação. É necessário antecipar que a maioria dos educadores não teve uma formação adequada para atuar especificamente com o tema da racialidade, assim como já aponta Cavalleiro em suas pesquisas (2003); sendo este um dos fatores que pode dificultar a melhoria das ações educativas quanto às questões etnico-raciais.

Referente à periodicidade que os professores trabalham os conteúdos relacionados à África e às questões afro-brasileiras, os educandos apontam que: $33 \%$ discutem no Dia da Consciência Negra (20 de Novembro); 16\% somente uma vez no bimestre; $10 \%$ no dia da abolição da escravatura; $5 \%$ uma vez no mês; $9 \%$ uma vez por semana; e a maioria dos professores não trabalha a temática (26\%); $1 \%$ não respondeu a questão. O que constatamos é que os professores ainda estão limitados a trabalhar os conteúdos relacionados à África apenas em datas comemorativas, o que é um indicador que os aspectos exigidos pelas Leis 10.639/03 e 11.645/08 não estão sendo implementados como se apontam em documentos oficiais e deliberações do MEC (Diretrizes Curriculares Nacionais para a Educaçãodas Relações Étnico-raciais e para o Ensino de História e Cultura afro-brasileira, 2004) entre outros. 
Quando perguntamos quais eram conteúdos já conhecidos sobre a África, os educandos responderam: $42 \%$ aos aspectos da história, 9\% sobre danças, 32\% sobre escravidão, $7 \%$ sobre religião, $4 \%$ comidas, 3\% sobre literatura, $1 \%$ aspectos biológicos, $2 \%$ personagens, $8 \%$ não apontaram nenhuma das opções anteriores e $1 \%$ não responderam. Notamos que os professores somente se detêm a história e a escravidão dos povos africanos, destacando pouco ou quase nada sobre as contribuições da população negra para a sociedade e das belezas da África e sua literatura.

A escassez do debate sobre os conteúdos exigidos nas Leis 10.639/03 e 11.645/08, dentro de sala de aula é alarmante e não podem ocorrer. Lembramos que as leis supracitadas garantem que os educandos tenham a formação estudantil alicerçada nos príncipios de igualdade, reconhecimento e valorizam das culturas, para aplicar no seu dia- a- dia, na vida acadêmica e profissional; desenvolvendo assim a sua cidadania e construindo uma sociedade mais justa e sem preconceito.

Outro aspecto que consideramos importante investigar era sobre o que os discentes gostariam que mudassem na escola, em relação às questões etnico-raciais. $\mathrm{O}$ que constatamos é a necessidade de superação à discriminação racial, assuntos mais aprofundados sobre a cultura negra para valorização da identidade etnica-racial; e, principalmente, o respeito às diferenças individuais e culturais dos sujeitos e o ensino de história que retrate a visão e as condições reais sobre como a população negra foi e é retratada na construção do Brasil. Para isto, ressalatamos a necessidade de formação docente para poderemos contribuir no exercício da cidadania dos indivíduos como sujeitos de direitos.

\section{A visão dos gestores e professores sobre a educação das relações etnico-raciais conforme as Leis 10.639/03 e 11.645/08}

O governo federal, reconhecendo a pluralidade sociocultural de nosso país, aprovou a Lei 10.639 de 09 de janeiro de 2003, bem como a Lei 11.645 de 20 de janeiro de 2008, ambas alterando a Lei 9.394/96. A promulgação dessas duas leis gerou no meio acadêmico um engajamento na luta pela construção de um currículo escolar mais crítico em relação àsquestões etnico-raciais e a reconstrução da história brasileira em relação aos negros. Quando questionamos aos gestores e professores quanto à importância da aplicabilidade das leis em debate, todos os gestores afirmam que são favoráveis a implementação das mesmas. Especificamente sobre os professores, 11 
afirmaram ter conhecimento das leis e somente um não conhece as mesmas. Mas, todos consideram importante a aplicabilidade das leis.

Os gestores afirmam que a implantação das Leis 10.639/03 e 11.645/08, em sua escola já ocorre há muitos anos. No entanto não é o que constatamos se compararmos os dados com as vozes dos educandos sobre a temática; uma vez que a maioria das vezes, o assunto é abordado em datas comemorativas como o Dia a abolição da escravatura e o Dia da Consciência Negra e também porque o assunto sempre está elencado sobre os aspectos relacionados à escravidão; o que em nosso entendimento não traz uma visão crítica sobre a contribuição dos negros a nossa sociedade e nem tão pouco retrata a improtância da África para o desenvolvimento econômico de muitos países e povos do mundo. Assim se expressam os gestores: "Desde que foi implantado no currículo nacional. O próprio MEC não dar muita ênfase"( D1); "Há mais de 18 anos" (D2); "Desde que entrei como diretor, os professores já trabalhavam a temática" (D3).

De acordo com Guedes et al (2013), integrar culturas é seguir por um caminho "pedregoso", porém não intransponível. O propósito neste caso é tornar visível socialmente à importância da cultura africana no decorrer da formação étnica brasileira. É fixar na sociedade a reflexão histórica a respeito da significância da influência africana na formação dos pilares étnico-sociais do país. Ratificamos as ideias de Guedes e Carvalleiro (2003) sobre a improtância do papel social da escola para a construção de uma educação antirracista e de valorização das culturas.

Assim como Cavalleiro (2003), entendemos que uma educação atirracista é um caminho para a "erradicação do preconceito, das discriminações e de tratamentos diferenciados", bem como pode proporcionar a "valorização da igualdade nas relações", a "reconquista de uma identidade positiva" de todas dentro da escola. A Educação Antirracista é também uma oportunidade para pessoas não negras e negras refletirem sobre a diversidade étnico-racial presente no Brasil; uma vez que poderão construir conhecimento acerda da história da África e das culturas afro-brasileiras presentes em nosso contidiano.

Ao questionarmos aos gestores se a educação para as relações etnico-raciais, especificamento, sobre a Áfricana e sua cultura poderia favorecer uma educação antirracista, desvelamos que 3 dos diretores firmam que sim e apenas 1 que se opõe, sendo contraditório a sua própria resposta sobre o primeiro questionamento que tratavam sobre a importância das legislações em debate. Estes dados nos exigiu perguntar se a escola ofereceu ou oferece formação aos educadores sobre a temática; os 
dados permitem-nos afirmar que esta dubiedade de resposta pode ser oriunda da falta de formação sobre o estudo: duas escolas ofereceram e duas não disponibilizaram formação aos educadores. Vale ainda apontar que três dos quatro gestores tiveram formação sobre a Educação para as relações etnico-raciais e somente um não teve. Quanto aos professores, e a formação especifíca para o ensino dos conteúdos exigidos pelas Leis 10.639/03 e 11.645/2008, sete dos professores afirmam que já tiveram e apenas cinco falaram que nunca tiveram.

Outro problema apontado pelos gestores é a falta de verbas para a compra de materiais pedagógicos que incentivem o aprendizado dos conteúdos sobre a África e suas contribuições, bem como para o desenvolvimento de uma educação para as relações etnico-raciais; e, o conteúdo apresentado nos livros didáticos. Dos doze professores participantes, 9 afirmam que a escola tem materiais adequados e 3 afirmam que a escola não tem materiais, centralizando o ensino por meio dos livros didáticos.

Entre as atividades desenvolvidas na escola, os quatro diretores afirmar que os educadores proporcionam ações para a construção de uma educação antirracista: "Visita a ex-quilombolas, palestras" (D1); "Os professores de história sempre trabalha em projetos com a temática" (D2); "Não temos projetos específicos relacionados à lei 10.630/03. Contudo, comemoramos em novembro o dia a cultura-afro com roda de capoeira e palestras" (D3); “Abordando o tema através de palestras”( D4) . Todavia, não os educandos apontaram que tais atividades precisam ser melhor direcionadas para que o objeto específico das legislações sejam oferecidos com aprofundamento e olhar crítico sobre as relações etnico-raciais. Só para lembrar, o educando A11 disse: “[...] devemos lembrar que negro também é gente.”

Também foi questionado se a escola promove algum evento que enfatizam a história da África e cultura afrobrasileira: os quatro gestores afirmam que sim e todos apontaram o que os educandos já haviam explicitado: sempre no mês de Novembro, quando se comemora o Dia da Consciência Negra, ou na semana do folclore. Construir o reconhecimento da sigularidade humana e a valorização da diversidade não se faz somente na edição de leis e decretos legais. Ela é feita pela materialização das leis, por meio de ações propositivas que possibilitem o educador assumir seu papel social e a reelaborar seus valores, refazer suas abordagens de ensino e reflexões críticas sobre o currículo escolar; por esta razão não podemos com práticas educativas que trata a educação para as relações etnico-raciais meramente em dias comemorativos, como se este assuntos não fosse um aspecto essencial de superação da discriminação racial e 
preconceito. A construção de um currículo escolar com perspectiva continuamente crítico favorece a construção do indivíduo consciente e participativo na sociedade. Isto já era apontado por Paulo Freire (1987) quando aborda a relevância social da escola sobre a formação da consciência crítica.

Ainda de acordo com Guedes et al (2013), a obrigatoriedade do ensino de História e cultura afro-brasileira e africana nas escolas de ensino fundamental e médio faz parte das discussões de entidades envolvidas com o Movimento Negro já há algum tempo. Mas, somente com a lei 10.639, criada em 2003, começou-se a pensar em políticas educacionais, bem como a escola em geral passou a pensar, e quando falamos em escola, é claro que, estamos incluindo tanto o quadro de professores, bem como os alunos e a comunidade, pois estes também se inserem no contexto escolar.

Segundo Guedes et al (2013), a preocupação com a situação do negro no Brasil assume uma importância ainda maior se comparada a outras nações, pois aqui a herança da África trazida com a diáspora está mais presente, porém menos valorizada. Essa desvalorização é uma característica facilmente constatada, pois basta olhar os dados sobre a sociedade através de lentes críticas que as discrepâncias sociais saltam aos olhos, sendo a população negra brasileira 53,6\% (composta por pardos $45 \%$ e pretos 8,6\%- IPEA, 2014) os que menos tem poder aquisitivo no Brasil (IPEA, 2014).

Sendo a população negra a maior parcela da população brasileira (negros 53,6\%) as questões vinculadas à história da África e suas contribuições à sociedade brasileira deveria ser um dos aspectos presentes no cotidiano escolar. Como a própria pesquisa nos possibilitou identificar, a maior população de educandos nas escolas públicas do estado, nas cidades pesquisadas, são negras e descendentes de membros que sofreram a exploração do modelo escravocrata que o Brasil teve por muitos anos. Neste contexto, podemos afirmar que esta população urge um clamor de reconhecimento e valorização nas escolas públicas. Caso contrário, a escola continuará a reforçar a desigualdade social e a favorecer a manutenção desta população a vulnerabilidade aos ataques racistas e preconceituosos em vários segmentos sociais, como por exemplo, a situação financeira, profissional, familiar e tantas outras.

Dos doze professores participantes, dez deles afirmam trabalhar com os conteúdos sobre a África e sua cultura no currículo escolar brasileiro, principalmente, por reconhecerem que este componente curricular favorecer o reconhecimento da população negra no Brasil e por formar a consciência crítica sobre a discriminação e o preconceito. 
Em relação aos conteúdos desenvolvidos em sala de aula pelos professores, podemos observar que os mesmos são diversificados. Listamos em ordem de citações, do maior para menor citação: Consciência negra (8); Literatura (8); Identidade negra (6); Comidas típias (6); Abolição da Escravatura (5); e, Heróis Negros (5).

Os dados apontados pelos educandos também apresentam tais conteúdos abordados pelos professores, todavia, questionamos se os mesmos estão sendo apresentados de maneira crítica e coesa com os princípios que alicerçam a Educação para as relações etnico-raciais? Para responder a esta questão, a pequisa deveria abarcar a observação da prática cotidiana dos professores, o que não foi possível de ser feito, deixando aqui a reflexão para posterior pesquisa. Mas, podemos elencar alguns outros questionamentos: se a educação escolar nestas escolas atinge um grau elevado de criticidade e o fortalecimento do reconhecimento da diversidade humana e as relações etnico-raciais, por que os discentes ainda apresentam experiências de preconceito e discriminação dentro do espaço escolar? Por que os educandos apontam que ainda é necessário o debate e a superação da discriminação?

Segundo Silva (2012), educar para as relações etnico-raciais trata-se de pensar a cidadania e os direitos de negros e negras, do Brasil. Nesse contexto, as ações afirmativas são um marco na ressignificação do pensamento racial brasileiro, elas refletem o momento em que, saindo da ideia de democracia racial, o governo é pressionado a reconhecer o racismo velado, característico da sociedade brasileira e a traçar estratégias para combatê-lo. Não obstante, Prado (2013), afirmar que não é possível que se tenha uma ideia equivocada de que apenas os governantes eleitos pelo povo são os atores da execução de Políticas Públicas que possam mudar o quadro de desigualdade social. Segundo Prado (2013, p. 83) “o cidadão precisa assumir seu papel como protagonismo, deixando de lado a mera atividade expectadora.” Dessa forma, não é possível pensar em Política Pública se não há como favorecê-la e fomentá-la nas bases, com formação critica sobre as relações macro política educacional.

De acordo com Pimentel et al (2016), vivemos num país onde a herança do preconceito racial é muito presente, apesar de haver certa negação ou omissão do problema. As marcas dessa herança cultural estão muitas vezes implícitas em letras de músicas, na mídia e até mesmo na Literatura Infantil. A manutenção de práticas educativas que mantém o currículo eurocêntrico não favorece a construção de práticas educativas que pautam pelos princípios de reconhecimento da diversidade etnico-racial brasileira e não favoreçam na construção de uma educação antirracista. Sendo assim, 
conclamamos que os professores, assim como Prado (2013), Cavalleiro (2003), Silva (2012) e Guedes et al. (2013) assumam o papel social para a construção de práticas e aexecução de um currículo multiculrutal como se prevê nas Leis 10.639/03 e 11.645/08.

Quando questionado se o livro didático aborda suficientemente os conteúdos desta temática, veremos nas falas de três professores opiniões muito diferentes: "O livro do $1^{\circ}$ ano e $2^{\circ}$ trazem os conteúdos específicos de história da África e Brasil africana"(P7); "De forma periférica"(P8); "Não acredito que ainda é suficiente a abordagem a respeito da temática"(P9). Essa problemática já havia sido apontada por Gonçalves (2016) e Santos e Prado (2014), pois o conhecimento da história negra e indígena, no caso dos livros didáticos, tem se restringido as informações já um tanto conhecidas e sem aprofundamento crítico. Nos antigos livros didáticos, os negros eram vistos, à época colonial, como indisciplinados, inferiores, excelentes para o trabalho braçal e objetos da exploração sexual dos seus senhores, e nos atuais não trazem com aprofundamento os temas a serem explorados em sala de aula. Outro problemática é que professores não recebem formação continuada sobre a temática como se prevê as Diretrizes Curriculares para o Ensino da História da África e suas contribuições (2004), e/ou não estudam ou pesquisam sobre o assuntos não são capazes de romper com valores e explicações passadas, reproduzindo o mesmo currículo eurocêntrico.

Quando perguntado se já houve na escola casos de discriminação contra professores quanto à etnia, 10 dos professores falaram que não; e dois afirmam que sim. Assim como já apontado pelos educandos, o racismo e o preconceito ainda estão presentes na escola e para superá-los, mesmo sendo, também, vivenciadas por alguns dos professores é necessário a construção de um currículo que valorize a diversidade etnico-cultura, presente na escola. De acordo com Guedes et al (2013), a escola neste ponto é compreendida como o berço dos conflitos, dessa conversação que proporciona a troca de experiência e é, nesta fase que entra a discussão da cultura afro-brasileira, que já deve estar integrada ao currículo escolar.

\section{Considerações finais}

Concluímos que a apesar da implementação das Leis Federais de $n^{0}$ 10.639/03 e 11.645/08, muitos professores ainda estão limitados a trabalhar as temáticas na maioria das vezes somente no Dia da Consciência Negra e/ou em outras datas comemorativas, com conetúdos centralizados sobre a escravidão do povo africano. É lamentável que o 
Brasil, com grande diversidade étnico-cultural tenha que criar Leis para que as escolas ensinem a história e a cultura de seu povo e sobre a sua própria miscigenação. Isto é resultado de uma educação eurocêntrica e branqueadora que a escola teve por muitos anos em retratar a história do Brasil, sem valorizar a cultura afro-brasileira e nem tampouco indígena.

$\mathrm{Na}$ atualidade, ainda existe muitas pessoas sendo vítimas de preconceito e racismo, havendo a necessidade das escolas desenvolverem alternativas pedagógicas para educar os jovens num caminho livre de preconceitos/discriminação. Acreditamos que no momento que o educando se sentir inserido em um ambiente que o valorize e reconheça seus ancestrais como, também, sujeitos construtores de nosso país, certamente, os educandos terão uma autoestima mais elevada e uma autoafirmação como negros e negras de uma nação miscegenada.

A educação para as relações etnico-raciais pode favorecer os educandos na construção da autoidentidade como sujeitos de direitos e prosseguir seus estudos e buscar melhores condições de vida, assim como os educandos desta pesquisa se expressam. Como diz Mandela, "a educação é a arma mais poderosa que você pode usar para mudar o mundo", somente por meio dela podemos alcançar os objetivos da Lei 10.639/03 e da 11.645/08. Sendo assim, conclamamos aos professores e as escolas que assumam suas responsabilidades sociais.

\section{REFERÊNCIAS}

ABRAMO, L. Desigualdades de gênero e raça no mercado de trabalho brasileiro. Cienc. Cult. vol.58, no.4, São Paulo, out./dez. 2006.

BRASIL. Lei de Diretrizes e Bases da Educação Nacional. Brasília: Senado Brasileiro. 1996.

Lei 10.639. Senado Brasileiro. Brasília, 2003.

11.645. Senado Brasileiro. Brasília. 2008.

Conselho Nacional de Educação. Resolução no 1, 2004. Institui as Diretrizes Curriculares Nacionais para a Educação das Relações etnico-raciais e para o ensino de História e Cultura afro-brasileira e Africana. Brasília. 2004. 
CAVALLEIRO, E. A educação anti-racista: compromisso indispensável para um mundo melhor. CAVALLEIRO, Eliane. (Org.). Racismo e anti-racismo na educação: repensando nossa escola. São Paulo: Summus/Selo Negro, 2003, p. 141-160.

DAXENBERGER, A. C. S. Possibilidades metodológicas para o ensino da educação para as relações étnico-raciais na educação básica: relatos de formação de adultos nos cursos de graduação da UFPB/CCA. Anais do III CNEPRE: Campina Grande, 2016.

FERNANDES, J. R. O. Ensino de História e Diversidade cultural: desafios e possibilidades. Cad. Cedes, vol. 25, n. 67, set./dez. Campinas, 2005, p. 378-388. Disponível em: <http://www.cedes.unicamp.br>. Acesso em: 02 abr. 2013.

FREIRE, P. Pedagogia do oprimido. $17^{\text {a }}$ ed. Rio de Janeiro, Paz e Terra,. 1987.

FREIRE, P. Pedagogia da autonomia. Paz e Terra: São Paulo, 1997.

GONÇALVES, L. R. D. Educação para as relações etnico-raciais e o combate ao racismo: imagens de livros didáticos. João Pessoa: UFPB. Revista Política e Trabalho, n 44, 2016. Disponível em:

<http://periodicos.ufpb.br/index.php/politicaetrabalho/issue/view/1844/showToc>. Acesso 30 jan. 2017.

GUALBERTO, M. A. M. Mapa da intolerância religiosa. 2011. Disponível em:<http://www.institutobuzios.org.br/documentos/Mapa\%20da\%0Intolerancia\%20Rel igiosa.PDF>. Acesso em: 28 jun. 2016.

GUEDES, E, NUNES, P, ANDRADE, T. O uso da lei 10.639/03 em sala de aula. Revista Latino-Americana de História, Vol. 2, nº. 6, ago. 2013. IBGE. Pnad. São Paulo, 2014.

IPEA. Situação da população negra por estado. Brasilia: IPEA, 2014.

MOURA, G. Ilhas negras num mar mestiço. In: Carta falas, reflexões, memórias. RIBEIRO, D. Brasília 4, n.13, 1994.

MORIN. Edgar. Os setes saberes necessários à educação do Futuro. Cortez: São paulo, 2001.

LIMA, M. B.; TRINDADE, A. L. da. Africanidades, currículo e formação docente: desafios e possibilidades. In: MELO, M. R. de.; LIMA, M. B.; LOPES, E. T. (Orgs.). Identidades e alteridades: debates e práticas a partir do cotidiano escolar. São Cristóvão: Editora UFS, 2009.

OLIVA, A. R. A História da África nos bancos escolares. Representações e imprecisões na literatura didática. Estudos Afro-Asiáticos, ano 25, n. 3, 200. PIBID BIOLOGIA /UFPB-CCA.

PRADO, E. Políticas Públicas educacionais e comunidades quilombolas: relações indissociáveis. In DAXENBERGER, A. C. S.; SÁ SOBRINHO, R. G. Comunidade 
Quilombolas: das reflexões às práticas de inclusão social. Editora UFPB:João Pessoa. 2013.

PIMENTEL, J. J. C.; SILVA, J. L.; SANTOS, N. A. M. S. Racismo na escola: um desafio a ser superado. 2016. Disponível em:

<http://serra.multivix.edu.br/wpcontent/uploads/2015/06/Racismo_Escola_um_desafio_ ser_superado_ped.pdf >. Acesso em: 10 ago. 2016.

SÁ, C. S.; AMARAL, S.T. As com unidades quilombolas no Brasil. In: ETICEncontro de iniciação Científica, 3, 2007. São Paulo. Vol. 3. Disponível em: $<$ http://intermas.unitoledo.br/revista/index. ETI/issue/view/33>. Acesso em: 30 set. 2016.

SANTOS, K. O.; PRADO, E. C.. O livro ddático da educação de jovens e adultos e os múltiplos olhares sobre a diversidade étnico-racial brasileira. In DAXENBERGER, A. C. S.; SÁ SOBRINHO, R. G. Comuniddades quilombolas e diversidade étnicoracial: diferentes olhares e perspectivas. Editora UFPB:João Pessoa. 2014.

SILVA, T. F. de O.. A dimensão étnico-racial na formação de professores/as: reflexões a partir da licenciatura em Letras da UNEB./ Tássia Fernanda de Oliveira Silva -Alagoinhas, 2013.118f.; Il. Dissertação (Mestrado em Crítica Cultural)Universidade do Estado da Bahia. Departamento de Educação. Colegiado de Letras. Campus II.

SOUZA, E. G. R. da S.; FERRAZ, M. R.; CHAVES, W. M. História e Cultura Afrobrasileira (lei $n^{\circ}$ 10.639/2003): Um desafio para a educação física escolar. In: RIBEIRO, T. L. (Org.). XI Encontro Fluminense de Educação Física Escolar, Niterói, RJ, 2006. Anais. Niterói: Universidade Federal Fluminense, Departamento de Educação Física e Desportos, p.435-443, 2007.

\section{Como referenciar este artigo}

DAXENBERGER, Ana Cristina Silva. As questões etnico-raciais em escolas estaduais na região do brejo paraibano. Revista on line de Política e Gestão Educacional, Araraquara, v.21, n.2, p. 363-382, maio-ago. 2017. Disponível em: <http://dx.doi.org/10.22633/rpge.v21.n.2.2017.9982>. ISSN: 1519-9029.

Submetido em: 17/06/2017

Aprovado em: 18/07/2017 